\title{
An early mid-latitude aurora observed by Rozier (Béziers, 1780)
}

\author{
Chiara Bertolin ${ }^{1}$, Fernando Domínguez-Castro ${ }^{2,3}$, and Lavinia de Ferri ${ }^{1}$ \\ ${ }^{1}$ Department of Mechanical and Industrial Engineering, Norwegian University of Science and Technology, \\ Trondeim, 7491, Norway \\ ${ }^{2}$ ARAID Foundation, 50018, Zaragoza, Spain \\ ${ }^{3}$ Departamento de Geografía y Ordenación del Territorio, Universidad de Zaragoza, 50009, Zaragoza, Spain
}

Correspondence: Chiara Bertolin (chiara.bertolin@ntnu.no)

Received: 7 January 2020 - Discussion started: 13 February 2020

Revised: 14 August 2020 - Accepted: 20 September 2020 - Published: 2 November 2020

\begin{abstract}
Aurora observations are an uncommon phenomenon at low and mid latitudes that, at the end of the 18th century, were not well known and understood. Low and mid geomagnetic latitude aurora observations provide information about episodes of intense solar storms associated with flares and outstanding coronal mass ejection (CME) and about the variation of the geomagnetic field. However, for many observers at mid and low latitudes, the features of a northern light were unknown, so they could easily report it as a phenomenon without explanation. In this work, we found that an earlier mid geomagnetic latitude aurora was observed in Beauséjour, close to Béziers $\left(43^{\circ} 19^{\prime} \mathrm{N}, 3^{\circ} 13^{\prime} \mathrm{E}\right)$, France, by the abbot François Rozier. He was a meticulous botanist, doctor and agronomist with a special interest in atmospheric phenomena. On 15 August 1780, from 19:55 to 20:07 (Universal Time), François Rozier observed a "phosphoric cloud". A careful analysis of the report indicates that he was reporting an auroral event. The recovery of auroral events at low and mid latitude during the 1780s is very useful for shedding light on solar activity during this period because there are few records of sunspot observations.
\end{abstract}

\section{Background and introduction}

Incursions of high-energy particles from space, mainly solar wind, strongly interact with the Earth's magnetosphere, causing ionization and excitation of atmospheric gases and auroral emissions (Brekke, 2013; Gonzalez et al., 1994). The aurora borealis is a spectacular phenomenon that has been recorded from the Assyrians and Babylonians (Stephenson et al., 2004; Hayakawa et al., 2016, 2019c) to nowadays.
However, it was not until 1733 that de Mairan (1733) suggested that the aurora could be caused by the solar atmosphere (Krivsky, 1984).

Low- and mid-latitude auroras (LMLAs) are usually associated with intense space weather events, frequently caused by coronal mass ejection (CME) (Gonzalez et al., 1994; Vázquez et al., 2006). This was the case with well-studied extreme space weather events such as those that occurred in September 1770 (Hayakawa et al. 2017a); the Carrington event in August/September 1859 (Green and Boardsen, 2006; Green et al., 2006; Humble 2006; Tsurutani et al., 2003; Cliver and Dietrich, 2013; Hayakawa et al., 2019a); the storm on 1872 February (Hayakawa et al., 2018; Silverman, 2008); and the extreme events in September 1909 (Hayakawa et al., 2019b), May 1921 (Hapgood, 2019; Silverman and Cliver, 2001; Love et al., 2019) or March 1989 (Allen et al., 1989) resulting in extreme magnetic disturbances and auroral displays at very low latitudes. It is important to note that extreme space weather events of these magnitudes can provoke important impacts on our highly technologically dependent society, especially in activities related to aviation, GPS signals, radio communication, and electric power grids (Baker et al., 2008).

Low- and mid-latitude aurora nights show an association with solar activity indices as sunspot records. This link was observed during the telescopic era (Silverman, 1992; Lockwood and Barnard, 2015; Lockwood et al., 2016) but also during the pre-telescopic era from the comparison with naked-eye sunspot reports (Hayakawa et al., 2017a; Bekli and Chadou, 2019). This relationship is due mainly to the highest frequency of LMLAs during the maximum and the decaying phase of the solar cycle (Gonzalez et al., 1994). 
Therefore, the mid-latitude aurorae, being footprints of solar CMEs, can be considered to be proxies for long-term solar activity. Nevertheless, LMLAs sometimes occurred in periods of low solar activity (Silverman, 2003; Willis et al., 2007; Vaquero et al., 2007, 2013; Garcia and Dryer, 1987; Hayakawa et al., 2020). These auroras are called "sporadic auroras".

Auroral catalogues are important tools for understanding the long-term interaction among the solar activity and the Earth's magnetosphere (Legrand and Simon, 1987; Silverman, 1992). In the last centuries many auroral catalogues have been developed, e.g. de Mairan (1733), Lovering (1866), Fritz (1873), Angot (1897), Tromholt (1902), Link (1962, 1964), Krivsky and Pejml (1988), Loysha et al. (1989) or Ordaz (2010). LMLAs, although rare, were recorded in these catalogues by professional and nonprofessional observers. During the 18th century, in Europe, there were some professional observers who were familiar with the phenomenon and who recorded auroras systematically, e.g. Francisco Salvà (Barcelona, Spain) (Vaquero et al., 2010) and Giuseppe Toaldo (Padua, Italy) (DomínguezCastro et al., 2016). Nevertheless, there were many sporadic observers who also recorded LMLAs unknowingly, cataloging them as strange and inexplicable phenomena. These sporadic reports are important for generating and extending LMLA catalogues but require an accurate analysis to avoid possible misinterpretations (Kawamura et al., 2016; Usoskin et al., 2017; Stephenson et al., 2019). Here, we analysed an observation made by the abbot François Rozier in 1780 , with enough detail and quantifiable information to understand whether he observed an LMLA or a different phenomenon.

\section{Methodology}

\subsection{The observer}

Jean-Baptiste François Rozier, (Lyon, 23 January 1734Lyon, 29 September 1793) (Fig. 1a) (Gutton and Bonnet, 1991) was a professor of botany and medicine at the University of Lyon who, after studying at the Jesuit college at Villefranche-sur-Saône, entered the Saint-Irénée seminary in Lyon. In 1771 Rozier moved to Paris to edit the Journal de Physique et d'Histoire Naturelle founded by Jacques Gautier d'Agoty; after becoming the journal owner, he renamed it the Journal d'Observations sur la Physique, l'Histoire Naturelle et sur les Arts et Métiers and later the Journal de Physique, where the original versions of many fundamental memoirs appeared (McKie, 1957). Rozier maintained the journal up to 1779 , when he devoted himself to the writing of the Cours d'agriculture (see below), a periodical that was edited by his nephew, the mineralogist and priest Jean-André Mongez (21 November 1750-May 1788). In 1779 he became prior of the abbey at Nanteuil-le-Haudouin (between
Paris and Reims), while in July 1780 Rozier bought an estate close in Beauséjour, in the suburbs of Béziers $\left(43^{\circ} 19^{\prime} \mathrm{N}\right.$, $3^{\circ} 13^{\prime} \mathrm{E}$ ), southern France (domaine de Beauséjour), to install his own model farm (1781). Here he could edit his Cours Complet d'Agriculture Théorique et Pratiqueou Dictionnaire Reisonné et Universel d'Agriculture (12 volumes in the form of a dictionary, of which 9 were by Rozier himself, 17811800 , and the last 2 were published after his death). Finally, he sold the property and in 1786 moved to Lyon, where he accepted a position as Director of the School of Agriculture and of the Pépinière (plant nursery) de la Province in 1788. Finally, he became constitutional curate of Sainte-Polycarpe parish in Lyon and was killed during the siege of the town on the night between 28 and 29 September 1793 (French Revolution).

Rozier was a member of the Académie de Lyon and thanks to his activity as editor of scientific journals was in contact with the most famous scientists and intellectuals of his time. He devoted his life to the observation of botanical or agricultural biological, chemical, physical and meteorological phenomena (e.g. temperature, atmospheric pressure observations with barometers of different diameters or states of the sky, such as thunder observations).

\subsection{The documentary source and the observation description}

The observation was described in the "Observations sur la physique, sur l'histoire naturelle et sur les arts, avec des planches en taille-douce" tome XVIII under the title "Observation sur une Nuée rendue phosphorique par une surabondance de l'électricité, vue de Beauséjour près de Béziers, le 15 Août" (About a cloud rendered phosphoric by an overabundance of electricity observed at Béziers on 15 August) (Rozier, 1781) (Fig. 1b). The most important fragments of the observation are reported below in our English translation, while the complete original French version is reported in Fig. 1b.

The closer the night approached, the more the clouds were pushed and accumulated towards the great chain of mountains of the third order that cross the low-Languedoc from east to west $[\ldots]$ At 20:05 it was completely night. It was at this moment that, examining the direction and the effects of the flashes, I noticed behind the slope of the hill, which on one side blocks the view from my house, a bright spot. This light did not look like that of a candle seen from afar, nor that which spreads from a forest or grass when they are set on fire. It seemed to me to have the whitish colour of phosphorus burning in the open air, or rather of that of mercury stirred in a tube without air. This bright spot gradually acquired volume and intensity. It imperceptibly formed an area, a phosphoric band that appeared to my eyes at a height of 3 


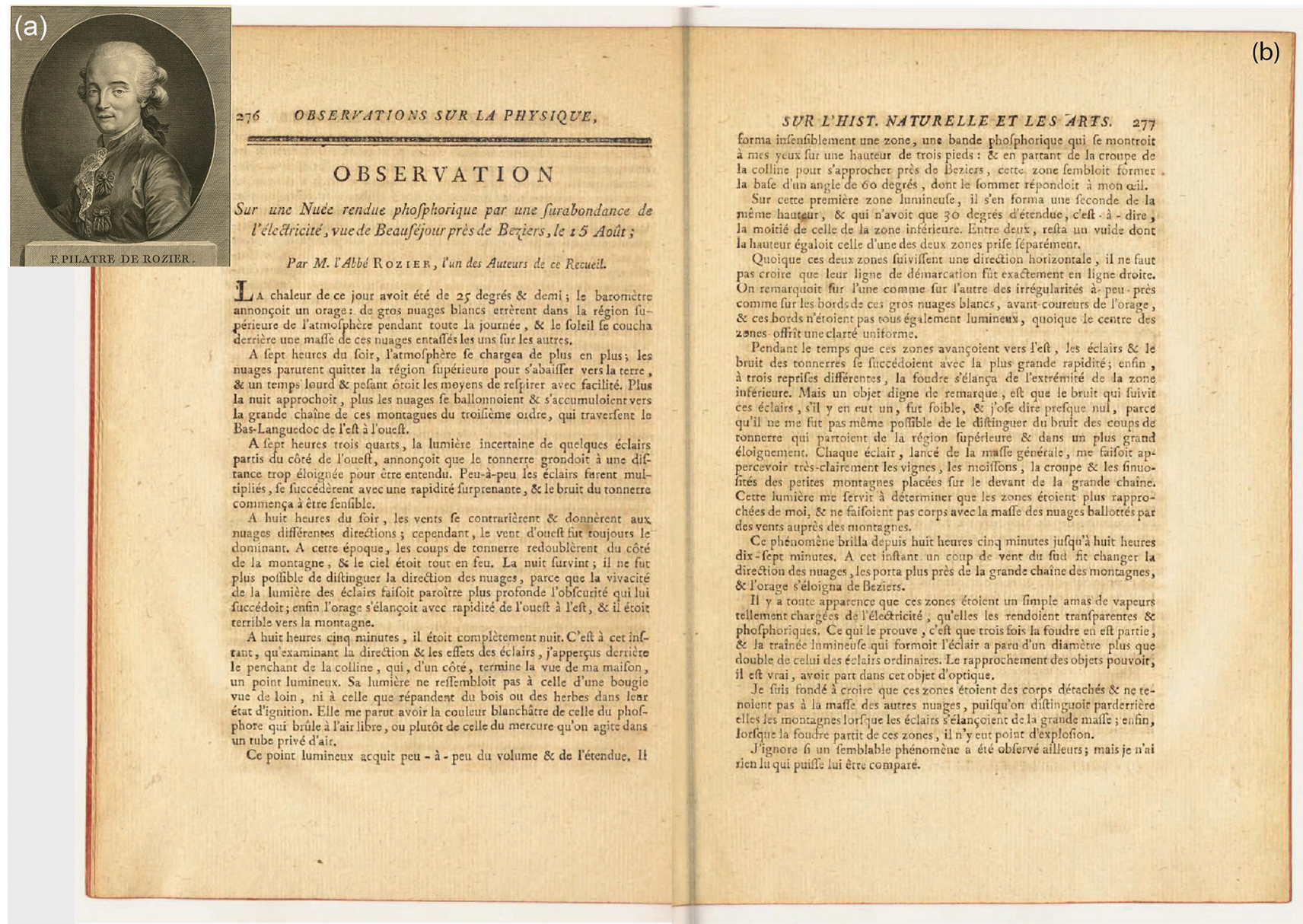

Figure 1. (a) Photographic portrait of abbot François Rozier (photo in the public domain). (b) The two printed pages reporting the aurora observation made by abbot François Rozier on 15 August 1780 in Béziers, France (Rozier, 1781).

feet: and starting from the top of the hill almost to Béziers, this area seemed to form the base of a $60^{\circ}$ angle, whose summit responded to my eye.

In this first luminous area, a second one of the same height formed, and it had only $30^{\circ}$ of extension [width], or half of that of the lower area. Between them remained a void whose height equalled that one of the two areas considered separately.

Even if these two zones followed a horizontal direction, it is not to believed that their line of demarcation followed exactly a straight line. We noticed on both some irregularities, roughly as on the edges of that big white cloud, storm forerunners, and these edges were not all equally bright even if the centre of the zones showed a uniform light.

During the period of time when these areas were moving eastward, the lightning and thunder noise were more rapid; finally, at three different times, a flash started from the end of the lower area. But an object worthy of note is that the noise follow- ing these flashes, if there was one, was weak and I would dare to say almost null because I could not distinguish it from the noise of the thunder that was starting from the upper region and from a greater distance. Every flash, launched by the general mass, made me clearly appreciate the vines, the crops, the top and the sinuosity of the small mountains located in front of the big chain.

That light helped me to understand that the areas were closer to me and did not belong to the mass of clouds pushed by the winds towards the mountain.

This phenomenon appeared from 20.05 until 20.17. In this instant a gust of wind from the south changed the direction of the clouds, bringing them closer to the big mountain chain, and the storm moved away from Béziers.

It would seem that these areas were a simple mass of vapours, only charged by electricity, which made them transparent and phosphoric. It is proven by the fact that three times the flash disappeared 
and the trail of light left by the flash appeared to be more than twice the diameter of normal flashes. The [apparent] proximity of the objects could, it is true, be due to these optical effects.

I am led to believe that these areas were detached entities [bodies] and that they did not belong to the mass of the other clouds because the mountains were visible behind them when the flash departed from the big mass; finally, when the flash started from these areas, there was no explosion.

I don't know whether such a phenomenon has been observed elsewhere; but I have never read anything that can be compared to it.

\section{Analysis of the observation}

\subsection{Hour of observation and Sun depression angle}

Rozier describes the starting (20:05) and ending (20:17) hour of his observation as local solar time (LST), i.e. the measure of local time as in use in the 18th century. The pendulum clocks locally could be synchronized following the daily data reported in the Ephemerides, with the time of sunrise, midday and sunset published yearly (Jeaurat, 1780). Given its longitude, these times correspond to 19:55 and 20:07 in Universal Time (UT) respectively. At these times the solar depression angle was 11.5 and $13.3^{\circ}$ respectively. Therefore, although Rozier described the observational conditions as if it had been "completely night", the observation started during the nautical twilight and concluded in the astronomical twilight. The calculation of the solar depression angle for the geographical coordinates in Béziers and the day of the observation has been performed using the HORIZONS Web-Interface of the American National Aeronautics and Space Administration (NASA) (https://ssd.jpl.nasa.gov/ horizons.cgi?s_type=1\#top, last access: 28 October 2020).

\subsection{Shape}

Regarding shape description, Rozier was very accurate. The main structure described by Rozier is that

it formed a zone, a phosphoric band [...] at a height of 3 feet $[\ldots]$ and finally it formed an angle of $60^{\circ}[\ldots]$ above this first luminous zone a second [zone] of the same height was formed, but with $30^{\circ}$ of extension only i.e. half of that of the lower zone. Between one and the other a void remained, the height of which matched that one of the two connected zones.

This description may fit with the report of the auroral form class without a ray structure, i.e. homogeneous arcs or uniform diffuse surfaces, and homogenous bands too Störmer (1955).
Nevertheless, the beginning of the aurora could resemble some aspect of an auroral sub-storm expansion (Ebihara et al., 2017; Stephenson et al., 2019) which is characterized by initial brightening of aurora, followed by a bulge expanding in all directions (Akasofu, 1964; Akasofu et al., 1965): "I noticed a luminous point $[\ldots]$ this luminous point acquired slowly [over time] volume and intensity". Moreover, Rozier recorded some flaming during the event:

in one or in the other zone I noticed irregularities, as well as on the edges of those big white clouds [i.e. general mass or bulge]. This edge was not homogeneously bright, although the centre was uniformly bright. In the time over which the zones moved eastward [...] a flash started from the end of the lower area [of the general mass or bulge].

\subsection{Colour}

He carefully mentioned the colour: "whitish colour of phosphorus burning in the open air". As stated by Stephenson et al. (2019), at low-mid geomagnetic latitude, northern lights have generally a higher probability of being observed if they are reddish; however, in case of an auroral display without enough brightness, it tends to appear whitish to the human eye. In addition, such an effect of the human eye is enhanced if the Moon is also present in the sky as the eye cannot be "dark adapted". Moreover, the whitish auroral colour may be explained by the enhancement of the $557.7 \mathrm{~nm}$ of oxygen with weak brightness or the oxygen mixture with other emissions as well (Ebihara et al., 2017; Stephenson et al., 2019). Examples of observation which confirm that LMLAs are whitish in colour during extreme space weather events are reported by Ebihara et al. (2017), Green and Boardsen (2006), Hayakawa et al. (2017b) and Willis et al. (1996). Rozier observed a white aurora: this made the phenomenon more unusual and increased the possibility of misinterpretation of the phenomenon by Rozier himself.

\subsection{Noise}

Silverman and Tuan (1973) said that, from observational evidence, the most likely sound accompanying auroral observations could derive from discharges generated by aurorally associated electric fields. Rozier, however, in his observation reported that "It appeared [to me] that these areas were a simple mass of steam, only charged by electricity, which made them transparent and phosphoric". However, he concluded by saying that "for three different times, a flash, with almost null noise, started from the end of the lower area [i.e. the bulge] [...] [and again] when the light flashed [...] there was no explosion”. This absence of sound recorded by Rozier discards a possible misinterpretation with other noisy atmospheric phenomena. 


\subsection{Moon}

Whether or not an aurora is outshone by the Moon depends on the lunar phase, the brightness of the aurora, and the angular distance between the Moon and the sky position occupied by auroral emission (Stephenson et al., 2019). Rozier does not report any information about the Moon, but the Moon was in the sky that day. The Moon on 15 August 1780 was full and rose at 19:25 (UT) at an azimuth angle of $111.4^{\circ}$ ESE direction, i.e. opposite with respect to the direction of observation of Rozier and close to the horizon. During the time Rozier observed the phenomenon, the Moon was at azimuth angle $116.5^{\circ}$ and elevation angle $3.4^{\circ}$ (at 19:55 UT), while at the end of his observation it was at azimuth angle $118.5^{\circ}$ and elevation angle $5.3^{\circ}$ (at 20:07 UT), therefore always in the ESE direction. The short time of the observation suggests that although the aurora was highly bright because Rozier could record it with full Moon in the sky (Stephenson et al., 2019; Hattori et al., 2019), because of the Moon rising above the horizon the light conditions could have hindered the visibility of the aurora as well as the presence of tropospheric clouds. In the literature several auroral observations are reported during full Moon, e.g. those observed on 18 February and on 12 November 1837 (Olmsted, 1837; Snow, 1842), those reported by Martin (1847) and Glaisher (1847) on 24 October of that year, and the event observed on 4 September 1908 described by Barnard (1910).

\subsection{Geomagnetic latitude}

We have calculated the temporal evolution of the geomagnetic latitude in Béziers for the night of the observation using the gufm1 geomagnetic model (Jakson et al., 2000). The geomagnetic latitude $\varphi$ equal to $50.18^{\circ} \mathrm{N}$ is obtained by Eq. (1) in the hypothesis of a dipolar configuration for the geomagnetic field.

$\varphi=\frac{\tan I}{2}$,

where $I$ is the magnetic inclination obtained from the gufm 1 model for the year 1780. This implies that the aurora is in the lower limit of the mid-latitude aurora or at the border for being defined as an LMLA, as this threshold in the literature is often around $50.00^{\circ} \mathrm{N}$ geomagnetic latitude.

\section{Discussion}

In the previous section we verified that Rozier observed an aurora on the night of 15 August 1780. According with the Angot catalogue (Angot, 1897), on this night the aurora was also observed at Regensburg (Germany; $49^{\circ} 01^{\prime} \mathrm{N}, 12^{\circ} 05^{\prime} \mathrm{E}$ ), $5.5^{\circ}$ further north than Béziers. The Angot catalogue has been extensively used on the reconstruction of auroral nights and as a proxy of the long-term geomagnetic variability. Nevertheless, it is important to note that Angot (1897) is a sec-

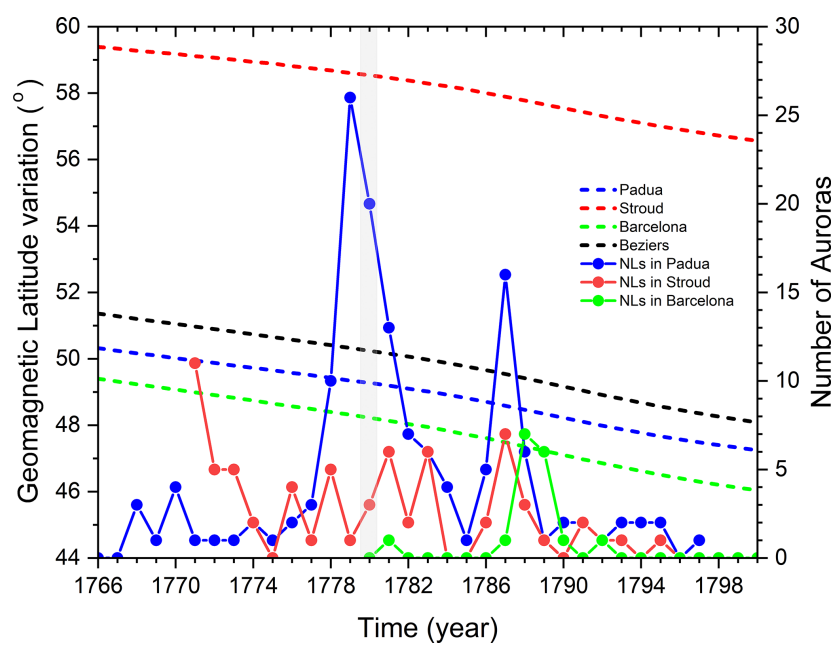

Figure 2. Geomagnetic latitude variations for Padua, Barcelona, Stroud and Béziers and yearly total auroras recorded in these places by Toaldo, Salva and Hughes. The grey column indicates the year of Rozier's auroral observation, 1780.

ondary source (the author was not witness to the facts he describes) and does not provide information on the primary sources he consulted for the elaboration of the catalogue. Secondary sources must be used carefully because they can include errors due to the transcription or interpretation of the primary source. For this reason, it is valuable to find primary sources that corroborate the information provided by Angot, especially during the nights on which Angot recorded an event in a single location, such as the night of $15 \mathrm{Au}-$ gust 1780 .

In addition, magnetic indexes were not available in 1780. The Ak index has in fact been available since 1844 (Nevanlinna and Kataja, 1993), the aa index since 1868 (Mayaud, 1980) and the geomagnetic IDV index (Svalgaard and Cliver, 2010) since 1835. For this reason, LMLA catalogues and sunspot numbers are used here as proxies of the geomagnetic activity in Rozier's time.

First the aurora catalogues at comparable latitudes were analysed. Then, they were compared with two existing coeval series of auroras homogeneously recorded at low latitude by trained observers such as Toaldo (1766-1797) (Padua, Italy; $45^{\circ} 24^{\prime} \mathrm{N}, 11^{\circ} 52^{\prime} \mathrm{E}$ ) (Domínguez-Castro et al., 2016) and Salvà (1780-1825) (Barcelona, Spain; 41 $23^{\prime} \mathrm{N}, 2^{\circ} 10^{\prime} \mathrm{E}$ ) (Vaquero et al, 2010). For differentiation purposes, the additional series of auroras observed by Thomas Hughes from Stroud, United Kingdom (mid-latitude $51.75^{\circ} \mathrm{N}, 2.22^{\circ} \mathrm{W}$ ) (Giles, 2005), has also been reported. Figure 2 shows the Toaldo, Salva and Hughes yearly total observations of auroras and the geomagnetic latitude respectively in Padua, Barcelona, Stroud and Béziers over the common 1766-1800 period. Rozier's observation was close to the maximum LMLA observed by Toaldo in Padua (1779). Nevertheless, no aurora was recorded by Salvà at Barcelona during 1780. 


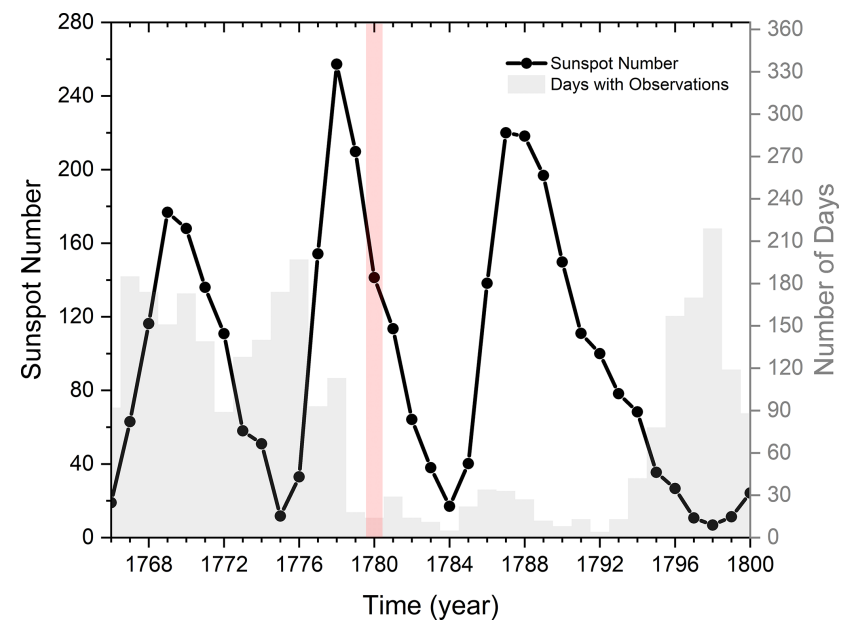

Figure 3. Annual total sunspot numbers and number of days with solar observations (SILSO, 2020, WDC sunspot number).

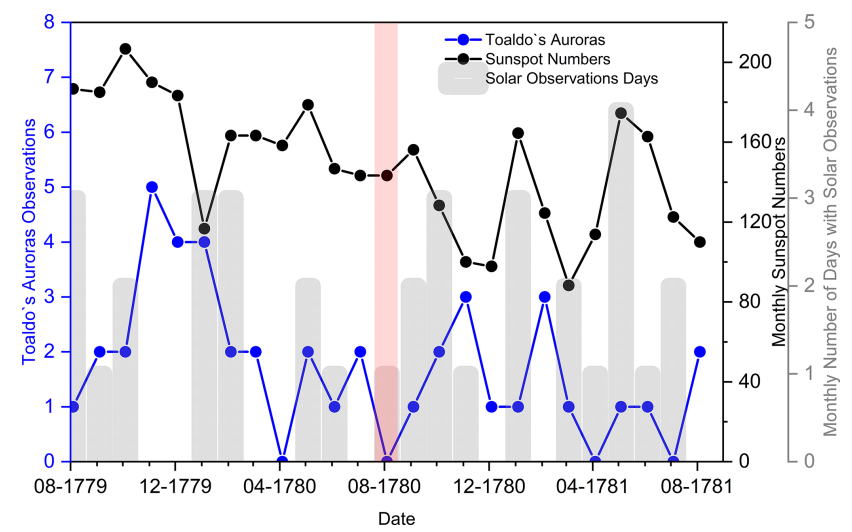

Figure 4. Monthly sunspot numbers, days with solar observations and auroras from Toaldo's catalogue from August 1779 to August 1781 .

At higher latitudes (Stroud) Hughes recorded a mean low activity of auroras for that year.

Figure 3 shows the sunspot number during the period 1766-1800. Rozier's observation was in the declining phase of solar cycle 3, 2 years after the maximum. This is a good moment to see LMLAs because long-lived coronal holes sources of high ionized particles in the solar wind - occur more frequently in the declining phase of the sunspot cycle (Verbanac et al., 2011; Lefèvre et al., 2016). It is important to note that Rozier's observation occurred in a period with few sunspot records. As we can see in Fig. 4, solar observations during the 1780s were rare, frequently below 30 observations per year. For this reason, any contribution to the knowledge of geomagnetic activity in this period is very beneficial.

Figure 4 shows at monthly resolution the solar activity and the auroras recorded in Padua from August 1779 to August 1781 . We can see that no aurora was observed during August, and only one solar observation was recorded in this month. The nearest solar observation was 30 August, when Johann Caspar Staudach reported four groups in the solar disk. The previous observation was made by P. Zeno on 12 July, recording one group (Vaquero et al., 2016). It means this event occurred in an interval without sunspot data for $48 \mathrm{~d}$.

\section{Conclusions}

We have found a record of an atmospheric phenomenon observed on 15 August 1780 in Beauséjour, close to Béziers $\left(43^{\circ} 19^{\prime} \mathrm{N}, 3^{\circ} 13^{\prime} \mathrm{E}\right)$, France, by the abbot François Rozier, who described thus: "big white cloud [...] whitish colour of phosphorus burning in the open air". Rozier was not an astronomer, and it is clear that he did not fully understand the phenomenon he was recording. Probably for this reason he recorded the event in minute detail to later discuss it with other academicians of his time. Thanks to this accuracy, we have been able to analyse quantitative information and facts that contribute to confirming that François Rozier observed a mid-latitude aurora that night. The aurora was observed during the nautical and astronomical twilight, it was white, and it was brilliant enough not to be outshone by the full Moon, which however was above the horizon in the ESE direction. It showed two bands and some rays, which could fit with the class of auroral forms of both homogeneous arcs/uniform diffuse surfaces and homogenous bands. Its temporal evolution could also resemble an auroral sub-storm expansion.

This auroral event contributes to expanding geomagnetic knowledge of the late 18th century period, in which geomagnetic and solar activity have high uncertainties due to few sunspot and LMLA observations reported from primary sources.

Rozier's record is a clear case of how a scientist from a research field far from astronomy or meteorology in the 18th century could record and publish descriptions of atmospheric phenomena that he did not fully understand but which he considered worth being documented. These sources are very valuable because they report details of infrequent and/or partially unknown atmospheric phenomena. In this case Rozier's report has contributed to expanding geomagnetic knowledge of a period with little information.

Data availability. The datasets generated for this study are available on request to the corresponding author.

Supplement. The supplement related to this article is available online at: https://doi.org/10.5194/angeo-38-1139-2020-supplement.

Author contributions. CB conceived the study, performed the analysis and drafted the manuscript with FDC, who wrote the final manuscript. LdF translated the original data and conducted the his- 
torical research used in the study as well as contributed to scientific discussion of the article together with $\mathrm{CB}$ and FDC.

Competing interests. The authors declare that they have no conflict of interest.

Acknowledgements. Credits for the use of sunspot data to the World Data Center SILSO, Royal Observatory of Belgium, Brussels, and for the HORIZONS Web-Interface to the American National Aeronautics and Space Administration (NASA) (https://ssd.jpl.nasa.gov/ horizons.cgi?s_type=1\#top).

Financial support. The research reported in this publication was supported through the financial support guaranteed by the Onsager Fellowship - Research Excellence Program at the Norwegian University of Science and Technology (NTNU) in Trondheim and the DRO500 project (PID2019-108589RA-I00) financed by the Ministry of Science and Innovation of the Spanish Government.

Review statement. This paper was edited by Margit Haberreiter and reviewed by two anonymous referees.

\section{References}

Angot, A.: The Aurora Borealis, D. Appleton \& Co., New York, 326 pp., 1897.

Allen, J., Frank, L., Sauer, H., and Reiff, P.: Effects of the March 1989 Solar Activity, EOS, 70, 1479-1488, 1989.

Akasofu, S. I.: The development of the auroral substorm, Planet. Space Sci., 12, 273-282, https://doi.org/10.1016/00320633(64)90151-5, 1964.

Akasofu, S. I., Kimball, D. S., and Meng, C. I.: The dynamics of the aurora-II Westward traveling surges, J. Atmos. Terr. Phys., 27, 173-187, https://doi.org/10.1016/0021-9169(65)90114-5, 1965.

Baker, D. N., Balstad, R., Bodeau, M., Cameron, E., Fennell, J. F., Fisher, G. M., Forbes, K. F., Kintner, P. M., Leffler, L. G., Lewis, W. S., Reagan, J. B., Small, A., Stansell, T. A., and Strachan, L.: Severe space weather events Understanding societal and economic impacts: A Workshop Report, National Academies Press, Washington, D.C., USA, https://doi.org/10.17226/12507, 2008.

Barnard, E. E.: Observations of the aurora, made at the Yerkes Observatory, 1902-1909, Astrophys. J., 31, 208==233, 1910.

Bekli, M. R. and Chadou, I.: Analysis of pre-telescopic sunspots and auroras from 8th to 16th century, Adv. Space Res., 64, 10111018, 2019.

Brekke, A.: Physics of the Upper Polar Atmosphere, 2nd Edn., Springer-Verlag, Berlin Heidelberg, 2013.

Cliver, E. W. and Dietrich, W. F.: The 1859 space weather event revisited: limits of extreme activity, J. Space Weather Spac., 3, A31, https://doi.org/10.1051/swsc/2013053, 2013.

de Mairan, J. J. D.: Traité physique et historique de l'aurore boréale, Suite des Mémoires de l'Académie royale des sciences, année M. DCCXXI, Paris, reprint, 1733.
Domínguez-Castro, F., Vaquero, J. M., Bertolin, C., Gallego, M. C., De la Guia, C., and Camuffo, D.: Aurorae observed by Giuseppe Toaldo in Padua (1766-1797), J. Space Weather Spac., 6, A21, https://doi.org/10.1051/swsc/2016016, 2016.

Ebihara, Y., Hayakawa, H., Iwahashi, K., Tamazawa, H., Kawamura, A. D., and Isobe, H.: Possible Cause of Extremely Bright Aurora Witnessed in East Asia on 17 September 1770, Space Weather, 15, 1373-1382, https://doi.org/10.1002/2017SW001693, 2017.

Fritz, H.: Verzeichniss Beobachteter Polarlichter, C. Gerold's Sohn, Wien, 1873.

Garcia, H. A. and Dryer, M.: The Solar Flares of February 1986 and the Ensuing Intense Geomagnetic Storm, Solar Phys., 109, 119-137, https://doi.org/10.1007/BF00167403, 1987.

Giles, H.: Aurora diaries, Astron. Geophys., 46, 4.31-4.34, https://doi.org/10.1111/j.1468-4004.2005.46431.x, 2005.

Glaisher, J. E.: On the aurora borealis, as it was seen on Sunday evening, October 24, 1847, at Blackheath, Lond. Edinb. Dublin Philos. Mag. J. Sci., 31, 369-372, https://doi.org/10.1080/14786444708645871, 1847.

Gonzalez, W. D., Joselyn, J. A, Kamide, Y., Kroehl, H. W., Rosoker, G., Tsuruani, B. T., and Vasyliuna, V. M.: What is a geomagnetic storm?, J. Geophys. Res., 99, 5771-5792, https://doi.org/10.1029/93JA02867, 1994.

Green, J. L. and Boardsen, S. A.: Duration and extent of the great auroral storm of 1859, Adv. Space Res., 38, 130-135, https://doi.org/10.1016/j.asr.2005.08.054, 2006.

Green, J. L., Boardsen, S. A, Odenwald, S., Humble, J., and Pazamickas, K. A.: Eyewitness reports of the great auroral storm of 1859, Adv. Space Res., 38, 145-154, https://doi.org/10.1016/j.asr.2005.12.021, 2006.

Gutton, J. P. and Bonnet, J. C. (Eds.): Les Lyonnaises dans l'Histoire, Privat, Toulouse, 1991.

Hapgood, M.: The Great Storm of May 1921: An Exemplar of a Dangerous Space Weather Event, Adv. Space Res., 17, 950-975, https://doi.org/10.1029/2019SW002195, 2019.

Hattori, K., Hayakawa, H., and Ebihara, Y.: Occurrence of Great Magnetic Storms on 6-8 March 1582, Mon. Not. R. Astron. Soc., 487, 3550-3559, https://doi.org/10.1093/mnras/stz1401, 2019.

Hayakawa, H., Mitsuma, Y., Ebihara, Y., Kawamura, A. D., Miyahara, H., Tamazawa, H., and Isobe, H.: Earliest datable records of aurora-like phenomena in the astronomical diaries from Babylonia, Earth Planet. Space, 68, 195, doi10.1186/s40623-0160571-5, 2016.

Hayakawa, H., Tamazawa, H., Ebihara, Y., Miyahara, H., Kawamura, A. D., Aoyama, T., and Isobe H.: Records of sunspots and aurora candidates in the Chinese official histories of the Yuán and Míng dynasties during 1261-1644, Publ. Astron. Soc. Jpn., 69, 65, https://doi.org/10.1093/pasj/psx045, 2017a.

Hayakawa, H., Iwahashi, K., Ebihara, Y., Tamazawa, H., Shibata, K., Knipp, D. J., Kawamura, A. D., Hattori, K., Mase, K., Nakanishi, I., and Isobe, H.: Long-lasting extreme magnetic storm activities in 1770 found in historical documents, Astrophys. J., 850, L31, https://doi.org/10.3847/2041-8213/aa9661, 2017b.

Hayakawa, H., Ebihara, Y., Willis, D. M., Hattori, K., Giunta, A. S., Wild, M. N., Hayakawa, S., and Toriumi, S.: The Great Space Weather Event during 1872 February Recorded in East Asia, Astrophys. J., 862, 15, https://doi.org/10.3847/1538-4357/aaca40, 2018. 
Hayakawa, H., Ebihara, Y., Willis, D. M., Toriumi, S., Iju, T., Hattori, K., Wild, M. N., Oliveira, D. M., Ermolli, I., Ribeiro, J. R., Correia, A. P., Ribeiro, A. I., and Knipp, D. J.: Temporal and Spatial Evolutions of a Large Sunspot Group and Great Auroral Storms Around the Carrington Event in 1859, Adv. Space Res., 17, 1553-1569, https://doi.org/10.1029/2019SW002269, 2019a.

Hayakawa, H., Ebihara, Y., Cliver, E. W., Hattori, K., Toriumi, S., Love, J. J., Umemura, N., Namekata, K., Sakaue, T., Takahashi, T., and Shibata, K.: The extreme space weather event in September 1909, Mon. Not. R. Astron. Soc., 484, 4083-4099, https://doi.org/10.1093/mnras/sty3196, 2019b.

Hayakawa, H., Mitsuma, Y., Ebihara, Y., and Miyake, F.: The Earliest Candidates of Auroral Observations in Assyrian Astrological Reports: Insights on Solar Activity around 660 BCE, Astrophys. J. Lett., 884, L18, https://doi.org/10.3847/2041-8213/ab42e4, 2019 c.

Hayakawa, H., Ribeiro, P., Vaquero, J. M., Gallego, M. C., Knipp, D. J., Mekhaldi, F., Bhaskar, A., Oliveira, D. M., Notsu, Y., Carrasco, V. M. S., Caccavari, A., Veenadhari, B., Mukherjee, S., and Ebihara, Y.: The Extreme Space Weather Event in 1903 October/November: An Outburst from the Quiet Sun, Astrophys. J. Lett., 897, L10, https://doi.org/10.3847/2041-8213/ab6a18, 2020.

Humble, J.: The solar events of August/September 1859 - Surviving Australian observations, Adv. Space Res., 38, 155-158, https://doi.org/10.1016/j.asr.2005.08.053, 2006.

Jakson, A., Jonkers, A. R. T., and Walker, M. R.: Four centuries of geomagnetic secular variation from historical records, Philos. T. R. Soc., A358, 957-990, https://doi.org/10.1098/rsta.2000.0569, 2000.

Jeaurat, E. S.: Connoissance des Temps pour 1'Année bissextile 1780, Publiée Par l'ordre de l'Académie Royale des Sciences, et calculée par M. Jeaurat, de la meme Académie, De l'Imprimerie Royale, Paris, 1780.

Kawamura, A. D., Hayakawa, H., Tamazawa, H., Miyahara, H., and Isobe, H.: Aurora candidates from the chronicle of Qíng dynasty in several degrees of relevance, Publ. Astron. Soc. Jpn., 68, 79, https://doi.org/10.1093/pasj/psw074, 2016.

Krivsky, L.: Long-term fluctuations of solar activity during the last thousand years, Sol. Phys., 93, 189-194, 1984.

Krivsky, L. and Pejml, K.: Solar activity, aurorae and climate in Central Europe in the last 1000 years, Publications of the Astronomical Institute of the Czechoslovak Academy of Sciences, Czech Republic, 1988.

Lefèvre, L., Vennerstrøm, S., Dumbovic, M., Vrsnak, B., Sudar, D., Arlt, R., Clette, F., and Crosby, N.: Detailed Analysis of Solar Data Related to Historical Extreme Geomagnetic Storms: 1868-2010, Sol. Phys., 291, 1483-1531, https://doi.org/10.1007/s11207-016-0892-3, 2016.

Legrand, J. P. and Simon, P. A.: Two Hundred Years of Auroral Activity (1780-1979), Ann. Geophys., 3, 161-168, 1987.

Link, F.: Observations et catalogue des aurores boréales apparues en Occident de 626 à 1600, Geofysica Sbornik, 10, 297-392, 1962.

Link, F.: Observations et catalogue des aurores boréales apparues en Occident de 1601 à 1700, Geofysica Sbornik, 12, 501-550, 1964.

Lockwood, M. and Barnard, L.: An arch in the UK, Astron. Geophys., 56, 4.25-4.30, https://doi.org/10.1093/astrogeo/atv132, 2015.
Lockwood, M., Owens, M. J., Barnard, L., Scott, C. J., Usoskin, I. G., and Nevanlinna, H.: Tests of Sunspot Number Sequences: 2. Using Geomagnetic and Auroral Data, Sol. Phys., 291, 28112828, https://doi.org/10.1007/s11207-016-0913-2, 2016.

Love, J. J., Hayakawa, H., and Clive, E. W.: Intensity and Impact of the New York Railroad Superstorm of May 1921, Adv. Space Res., 17, 1281-1292, https://doi.org/10.1029/2019SW002250, 2019.

Lovering, J.: On the periodicity of the Aurora Borealis, Mem. Am. Acad. Arts Sci., 10, 9-351, 1866.

Loysha, V. A., Krakovetsky, Y. K., and Popov, L. N.: Aurorae: Catalogue from IV to XVIII centuries, Acad. Sci. USSR Sov. Geophys. Comm., 1, 1-10, 1989.

Mayaud, P. N. (Ed.): A Historical Review of Past Indices, in: Derivation, Meaning, and Use of Geomagnetic Indices, American Geophysical Union, Washington, D.C. USA, 4-16, 1980.

Martin, K. B.: Aurora Borealis, Royal Harbour of Ramsgate, Nautical Mag., 642-644, 1847.

McKie, D.: "The "Observations" of the Abbé François Rozier (1734-93)”, Ann. Sci., 13, 73-89, https://doi.org/10.1080/00033795700200071, 1957.

Nevanlinna, H. and Kataja, E.: An extension of the geomagnetic activity index series aa for two solar cycles (1844-1868), Geophys. Res. Lett., 20, 2703-2706, https://doi.org/10.1029/93GL03001, 1993.

Olmsted, D.: Observations on the aurora borealis on Jan. 25, 1837 , Am. J. Sci. Arts, 32, 176-181, 1837.

Ordaz, J.: Auroras boreales observadas en la Península Ibérica, Baleares y Canarias durante el siglo XVIII, Treb. Mus. Geol. Barcelona, 17, 45-110, 2010.

Rozier, J. B. F.: Sur une Nuée rendue phosphorique par une surabondance de l'electricitè, vuede Beausejour près de Beziers, le 15 Août, Observations sur la physique, sur l'Histoire naturelle er sur les arts, avec des planches en taille-douce, Paris, tome XVIII, 276-277, 1781.

SILSO: World Data Center - Sunspot Number and Long-term Solar Observations, Royal Observatory of Belgium, on-line Sunspot Number catalogue, available at: http://www.sidc.be/silso/, last access: 28 October 2020.

Silverman, S. M.: Secular variation of the aurora for the past 500 years, Rev. Geophys., 30, 333-351, https://doi.org/10.1029/92RG01571, 1992.

Silverman, S. M.: Sporadic auroras, J. Geophys. Res., 108, 8011, https://doi.org/10.1029/2002JA009335, 2003.

Silverman, S. M.: Low-latitude auroras: The great aurora of 4 February 1872, J. Atmos. Sol.-Terr. Phy., 70, 1301-1308, https://doi.org/10.1016/j.jastp.2008.03.012, 2008.

Silverman, S. M. and Cliver, E. W.: Low-latitude auroras: the magnetic storm of 14-15 May 1921, J. Atmos. Sol-Terr. Phy., 63, 523-535, https://doi.org/10.1016/S1364-6826(00)00174-7, 2001.

Silverman, S. M. and Tuan, T. F.: Auroral Audibility, Adv. Geophys., 16, 155-266, https://doi.org/10.1016/S00652687(08)60352-0, 1973.

Snow, R.: Observations of the Aurora Borealis. From September 1834 to September 1839, Moyes \& Barclay, London, 1842.

Stephenson, F. R., Willis, D. M., and Hallinan, T. J.: The earliest datable observation of the aurora borealis, Astron. Geophys., 45, 15-17, https://doi.org/10.1046/j.1468-4004.2003.45615.x, 2004. 
Stephenson, F. R., Willis D. M., Hayakawa, H., Ebihara, Y., Scott, C. J., Wilkinson, J., and Wild, M. N.: Do the Chinese Astronomical Records Dated AD 776 January 12/13 Describe an Auroral Display or a Lunar Halo? A Critical Re-examination, Sol. Phys., 294, 36, https://doi.org/10.1007/s11207-019-1425-7, 2019.

Störmer, C.: The Polar Aurora, Oxford University Press, Oxford, 1955.

Svalgaard, L. and Cliver, E. W.: Heliospheric magnetic field 1835-2009, J. Geophys. Res., 115, A0911, https://doi.org/10.1029/2009JA015069, 2010.

Tromholt, S.: Catalog der in Norwegen bis Juni 1878 beobachteten Nordlichter, Dybwad, Christiana, 452 pp., 1902.

Tsurutani, B. T., Gonzalez, W. D., Lakhina, G. S., and Alex, S.: The extreme magnetic storm of 1-2 September 1859, J. Geophys. Res., 108, 1268, https://doi.org/10.1029/2002JA009504, 2003.

Usoskin, I. G., Kovaltsov, G. A., Mishina, L. N., Sokoloff, D. D., and Vaquero, J.: An Optical Atmospheric Phenomenon Observed in 1670 over the City of Astrakhan Was Not a Mid-Latitude Aurora, Sol. Phys., 292, 15, https://doi.org/10.1007/s11207-0161035-6, 2017.

Vaquero, J. M., Trigo, R. M., and Gallego, M. C.: Sporadic aurora from Spain, Earth Planet. Space, 59, 49-51, https://doi.org/10.1186/BF03352061, 2007.
Vaquero, J. M., Gallego, M. C., Barriendos, M., Rama, E., and Sanchez-Lorenzo, A.: Francisco Salva's auroral observations from Barcelona during 1780-1825, Adv. Space Res., 45, 13881392, https://doi.org/10.1016/j.asr.2010.02.009, 2010.

Vaquero, J. M., Gallego, M. C., and Domínguez-Castro, F.: A possible case of Sporadic Aurora in 1843 from Mexico, Geofis. Int., 52, 87-92, 2013.

Vaquero, J. M., Svalgaard, L., Carrasco, V. M. S., Clette, F., Lefèvre, L., Gallego, M. C., Arlt, R., Aparicio, A. J. P., Richard, J.-G., and Howe, R.: A revised collection of sunspot group numbers, Sol. Phys., 291, 3061-3074, https://doi.org/10.1007/s11207016-0982-2, 2016.

Vázquez, M., Vaquero, J. M., and Curto, J. J.: On the Connection between Solar Activity and Low-Latitude Aurorae in the Period 1715-1860, Sol. Phys., 238, 405-420, 2006.

Verbanac, G., Vrsnak, B., Veronig, A. M., and Temmer, M. B.: Equatorial coronal holes, solar wind high speed strams, and their geoeffectiveness, Astron. Astrophys., 526, A20, https://doi.org/10.1051/0004-6361/201014617, 2011.

Willis, D. M., Stephenson, F. R., and Singh, J. R.: Auroral observations on AD 1770 September 16: The earliest known conjugate sightings, Q. J. Roy. Astron. Soc., 37, 733-742, 1996.

Willis, D. M., Stephenson, F. R., and Huiping Fang: Sporadic aurorae observed in East Asia, Ann. Geophys., 25, 417-436, https://doi.org/10.5194/angeo-25-417-2007, 2007. 